\title{
Article \\ Application of Machine Learning to Include Honking Effect in Vehicular Traffic Noise Prediction
}

\author{
Daljeet Singh ${ }^{1, *}$, Antonella B. Francavilla ${ }^{2}\left(\mathbb{D}\right.$, Simona Mancini $^{3}$ and Claudio Guarnaccia ${ }^{2, *}(\mathbb{0})$ \\ 1 Department of Mechanical Engineering, Thapar Institute of Engineering and Technology, Patiala 147004, India \\ 2 Department of Civil Engineering, University of Salerno, 84084 Fisciano, Italy; afrancavilla@unisa.it \\ 3 Department of Information Engineering, Electric Engineering and Applied Mathematics, \\ University of Salerno, 84084 Fisciano, Italy; smancini@unisa.it \\ * Correspondence: daljeet.singh@thapar.edu (D.S.); cguarnaccia@unisa.it (C.G.)
}

Citation: Singh, D.; Francavilla, A.B.;

Mancini, S.; Guarnaccia, C.

Application of Machine Learning to Include Honking Effect in Vehicular Traffic Noise Prediction. Appl. Sci. 2021, 11, 6030. https://doi.org/ 10.3390/app11136030

Academic Editor:

Sławomir K. Zieliński

Received: 5 May 2021

Accepted: 25 June 2021

Published: 29 June 2021

Publisher's Note: MDPI stays neutral with regard to jurisdictional claims in published maps and institutional affiliations.

Copyright: ( $\odot 2021$ by the authors Licensee MDPI, Basel, Switzerland. This article is an open access article distributed under the terms and conditions of the Creative Commons Attribution (CC BY) license (https:// creativecommons.org/licenses/by/ $4.0 /)$.
Featured Application: Machine learning techniques are calibrated on a dataset of sound levels in urban areas in India, with relevant honking occurrences. The best model chosen will improve the prediction of road traffic noise in similar cases, with respect to standard models that neglect the effects of honking.

Abstract: A vehicular road traffic noise prediction methodology based on machine learning techniques has been presented. The road traffic parameters that have been considered are traffic volume, percentage of heavy vehicles, honking occurrences and the equivalent continuous sound pressure level. $L_{e q}$ A method to include the honking effect in the traffic noise prediction has been illustrated. The techniques that have been used for the prediction of traffic noise are decision trees, random forests, generalized linear models and artificial neural networks. The results obtained by using these methods have been compared on the basis of mean square error, correlation coefficient, coefficient of determination and accuracy. It has been observed that honking is an important parameter and contributes to the overall traffic noise, especially in congested Indian road traffic conditions. The effects of honking noise on the human health cannot be ignored and it should be included as a parameter in the future traffic noise prediction models.

Keywords: road traffic noise; honking; machine learning; prediction; modelling

\section{Introduction}

The number of vehicles on the roads has been increasing exponentially, both in developing and developed countries. The reasons are consumerism, reduced prices, finance options, competition and the requirement of faster and convenient transport. An inevitable outcome of this continuous production and buying of these vehicles, especially the private ones, has been an increase in the noise and air pollution levels due to the hard traffic congestion, especially in critical areas of the cities [1-3]. The effects of air pollution are well known to the general public. To address the problem of environmental pollution, many predictive models and experimental studies have been developed for the traffic management as efficient solution to reduce vehicle journey times and, consequently, environmental impact. For instance, in [4], carbon dioxide $\left(\mathrm{CO}_{2}\right)$ emissions and unnecessary fuel consumption are addressed in the framework of route management for autonomous vehicles in urban areas. Conversely, there is a relatively lesser awareness of the harmful effects of traffic noise on the human population. Some of the adverse effects [5-8] include sleep disturbance, speech interference, annoyance, cardio-vascular effects and loss of fertility. In rare cases, such as with traffic policemen who are exposed to high sound pressure levels and long-term road traffic noise, hearing loss has also been observed [9]. As for the prediction of traffic volumes and the adoption of traffic management strategies to reduce noise pollution levels, a lot of research has been done on the effects of noise 
on human health $[10,11]$. Traffic noise prediction models play a very important role not only in the design and modification of road and traffic infrastructure [12] but also in the assessment of the noise level, based on certain critical parameters. Different types of traffic noise prediction models include country or region-specific models like the "Federal Highway Administration model" (FHWA, USA), the "UK Calculation of Road Traffic Noise" (CoRTN, UK), the "Acoustical Society of Japan Road Traffic Noise model" (ASJ, Japan) and the "Richtlinien für den Lärmschutz an Straben" (RLS-90, Germany). A critical review of the most used models can be found in [13-16]. Other categories of models include static and dynamic, stochastic and deterministic and artificial intelligence or machine learning based models [17-22]. In particular, several applications to traffic noise prediction can be found in literature, for instance [23-27], in which the authors adopt artificial intelligence techniques, such as artificial neural networks (ANN) and genetic algorithms (GA).

In most recent studies, hybrid models combining systems of ANN and fuzzy interference systems (FIS) (i.e., adaptive neuro fuzzy inference system-ANFIS) have been developed too [28]. Other hybrid models are represented by the integration between time series analysis techniques and ANN [29].

The different parameters that are generally considered in these models are traffic volume (number of vehicles per unit of time), percentage of heavy vehicles, average speed of vehicles, tyre-road interaction, building height, road width and gradient etc. One parameter that has generally been not considered and is quite prevalent in the Indian road conditions is honking noise.

The relevance of the honking in the Indian scenario has been demonstrated in several studies. In [30], for example, it is reported how the expansion of the transportation industry in the city of Nagpur led to an increment of 5-6 dBA in noise level, 4-6 times in honking and 1.7 times in traffic volume.

The Indian roads traffic conditions are quite different because of the size of the population, topography of the roads, vehicle types and conditions, driving habits and culture. Because of the congested traffic conditions and anxious drivers, the effect of honking on the overall traffic noise and its effects on the drivers, pedestrians, cyclists, traffic police personnel, nearby shopkeepers and residents needs to be considered. In this heterogeneous composition of traffic, horn events get to increase noise level $\left(L_{\text {den }}\right)$ up to $0.5-13 \mathrm{dBA}$ compared to homogenous traffic conditions [31]. Therefore, the prediction models used for homogenous traffic conditions are not applicable in this heterogeneous context. Thus, to increase the accuracy of noise prediction models, considering honking is required.

Some models considering honking have been developed by using regression model and statistical analysis [32], others by introducing a factor for horn correction, with respect of level of service (LOS), in traffic noise models such as CRTN, FHWA, and RLS 90 [31].

In the present work, an attempt has been made to include the honking effect in the traffic noise prediction model developed using machine learning methods. In particular, four different techniques have been selected, calibrated and tested on a case study experimental dataset collected in Patiala city, India. A comparison of these techniques on the basis of criteria of mean square error, correlation coefficient, coefficient of determination and accuracy has also been presented.

\section{Materials and Methods}

\subsection{Dataset and Sites Description}

The data used in this paper has been collected on the busy urban roads of the Patiala city in India (Figure 1). Besides the equivalent continuous sound pressure level $\left(L_{e q}\right)$, the data collection included the parameters traffic volume $(\mathrm{Q})$, percentage of heavy vehicles $(\mathrm{P})$ and total honking occurrences $(\mathrm{H})$ that have been used to calibrate and test the machine learning models. These parameters have been collected manually using videography at five different identified sites, highlighted in Figure 1, on the basis of congestion, presence of honking noise and proximity to resident population. For each video, the numbers of light 
and heavy vehicles have been annotated, as well as the number of honks in each $15 \mathrm{~min}$ measurement.

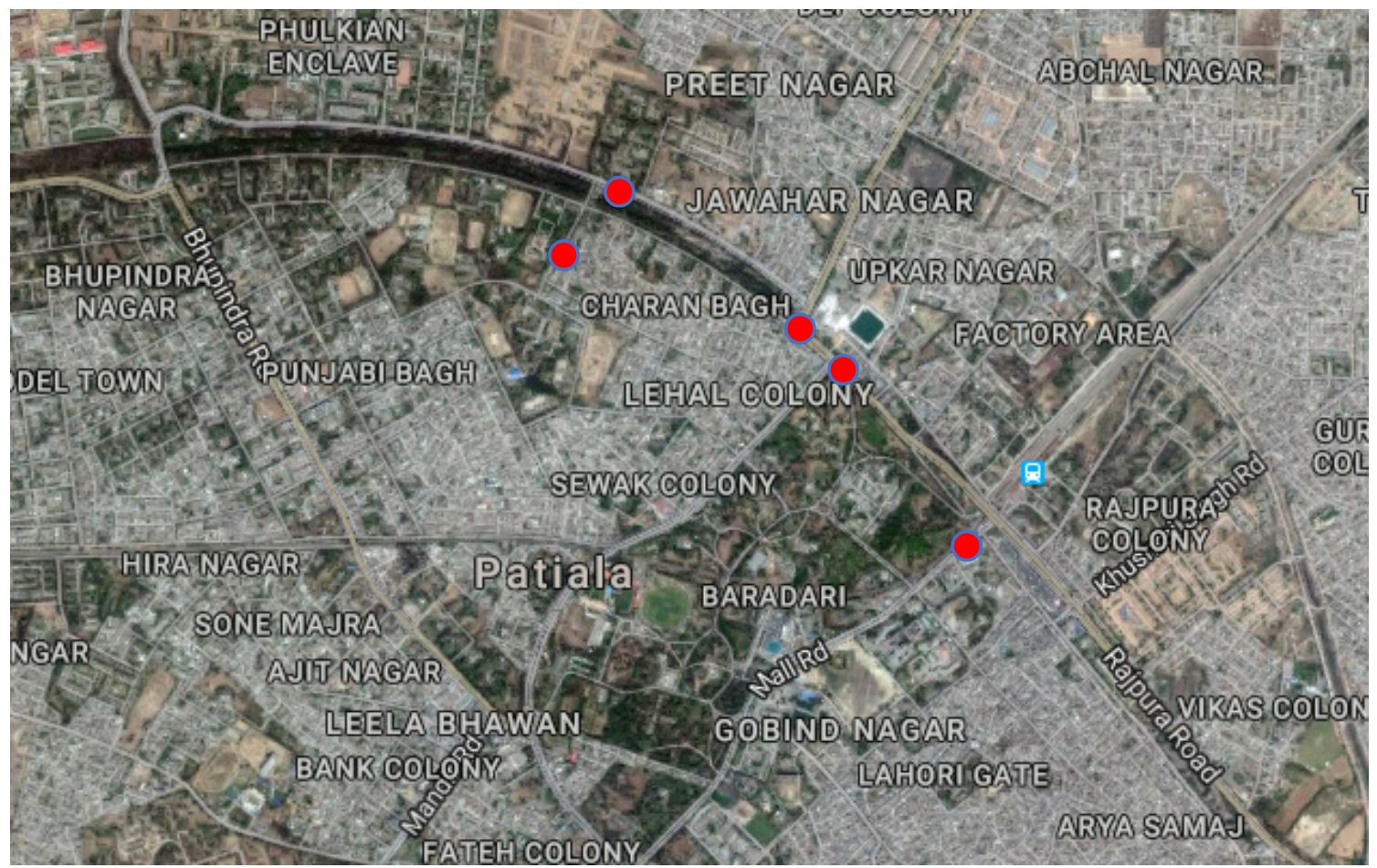

Figure 1. Area under study and sites of measurement (courtesy of Google Maps®).

In order to include the effect of horn noise in the prediction model, the number of honking events per 15 min was recorded. The values of the equivalent sound pressure level ( $L_{e q}$ in dBA) have been experimentally measured using a sound level meter (SLM, B\&K make, 2250). The sound level meter used was a class 1 integrating type, which meets with the IEC specifications (IEC 61672-1: 2002, International Electrotechnical Commission, 2002) [33]. The SLM was mounted on a tripod (in order to avoid the human body impedance effects), at a height of $1.2 \mathrm{~m}$ above the ground level [34] and at a distance of $1 \mathrm{~m}$ from the edge of the road where the traffic noise measurements were taken.

A brief description of the sites is given below.

Site 1: This site is located near the Hanumaan Temple, on the road connecting the Mini-secretariat and Gurudwara (a Sikh temple) Dukhniwaran Sahib (Figure 2a). The road has one-way traffic with a median/divider in the middle. The traffic is free-flowing with all types of vehicles plying on the road. There are no traffic lights or a roundabout near the measurement point. The noise generation is mainly due to the vehicle noise and tyre-road interaction noise. There is a thick belt of trees on one side of the road, which leads to noise attenuation by absorption due to the thick foliage.

Site 2: The site consists of a two-way road near the Modi Temple, connecting the Passy road to the State College road (Figure $2 b$ ). There is free-flowing traffic, with mainly cars and two-wheelers, and no traffic congestion. On one side, there is open land of the Modi temple ground with some sparse trees and boundary wall. Thus, there is some noise attenuation happening due to air-absorption. On the other side there are residential houses, mostly double storied, that may provide some noise attenuation.

Site 3: It consists of the road connecting the Gurudwara Dukhniwaran Sahib with the Passy road (Figure 2c). The speed of the vehicles is low here because of a narrow section through which the vehicles enter and also because of some fruit stalls and shops nearby. Due to the low speed and some congestion, more honking events have been observed.

Site 4: It is located on the road in front of the main entrance of Gurudwara Dukhniwaran Sahib (Figure 2c). The road is a one-way road with a median/divider in the middle. 
The traffic volume is very high as the vehicles arrive from different sections of the city and converge here to pass through this bottle-neck section and then go to Mini-secretariat road or the Sirhind road. There is a large number of heavy vehicles passing through this section as the vehicles coming from bus stand or other areas move out of the city using this road, to reach the Sirhind road and then subsequently to the national highway. On one side there is the Gurudwara Sahib main premises and the outer boundary wall, and on the other side, there are shops. High traffic noise levels are observed here due to the large traffic volume as well as honking.

Site 5: The site is situated near the Patiala Bus stand (Figure 2d). A lot of cars, two wheelers and three wheelers pass through this section. The speed of the vehicles is low due to the traffic congestion, as people come here to pick and drop passengers at the bus stand. This also leads to the highest number of horns/honking events observed here giving rise to high noise levels.

A description of the data collected at the above sites, with some statistical analysis and insights into the same is presented below.

The data was collected for 10 days at each site, with 15 min time span, so a dataset of 50 days has been obtained for all the five sites. A resume of the data main statistics is reported in Table 1, while the full dataset is reported in Appendix A.

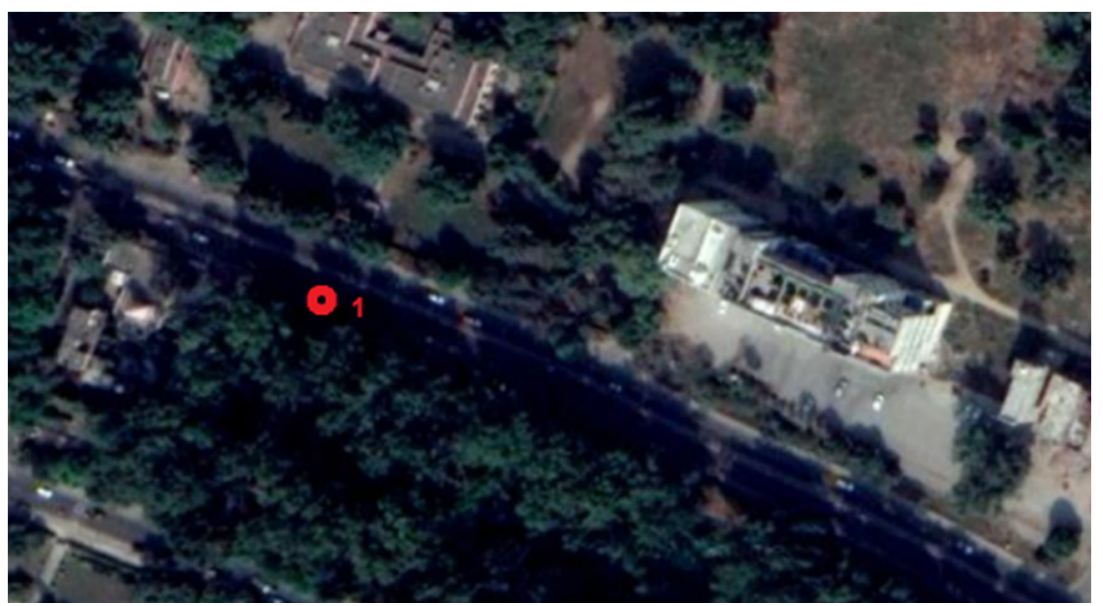

(a)

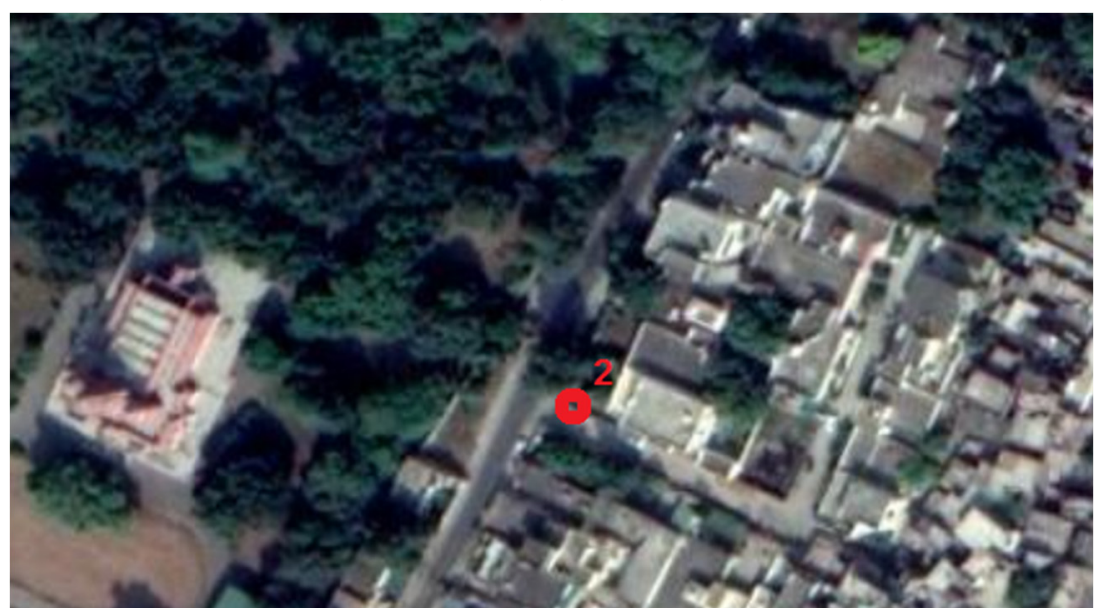

(b)

Figure 2. Cont. 


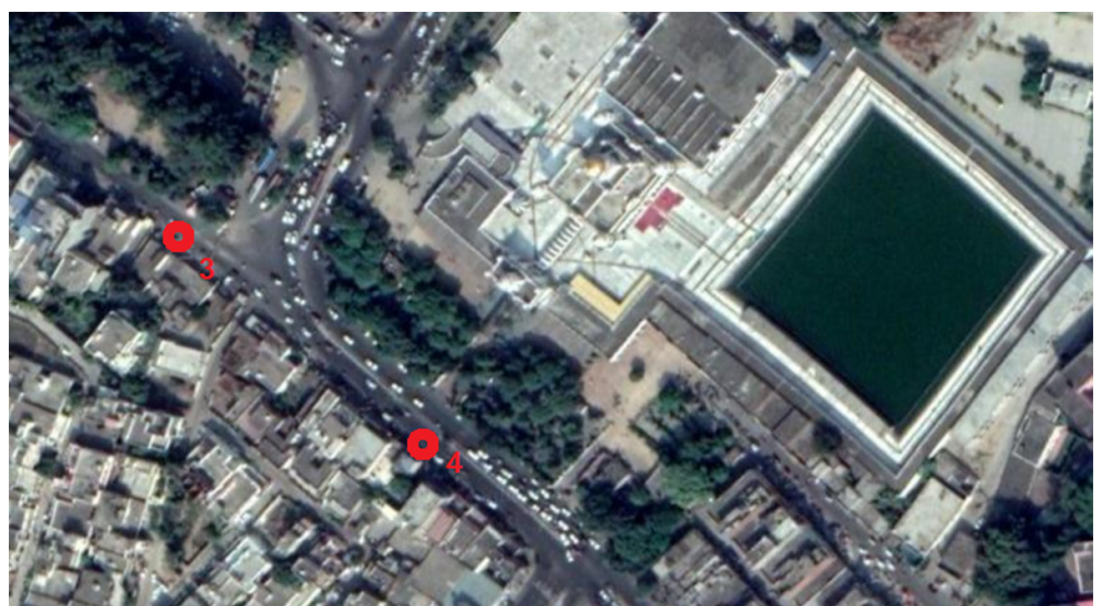

(c)

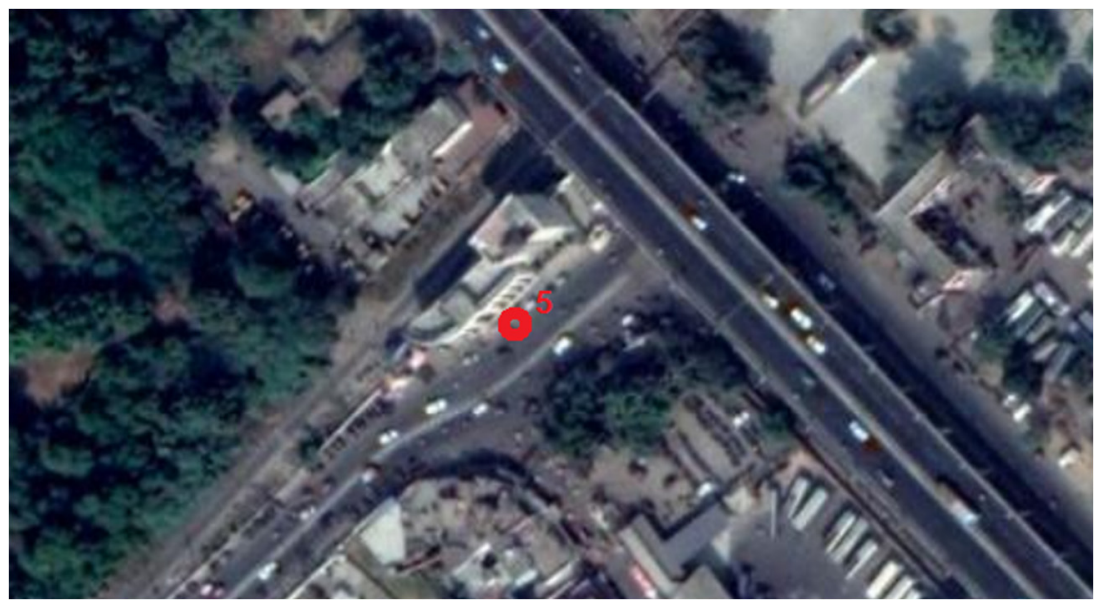

(d)

Figure 2. Localization of the identified sites, respectively site 1 (a), site 2 (b), site 3 and 4 (c), site 5 (d).

Table 1. Resume of the main statistics of data and parameters used in the calibration and testing of the models. All the features have been measured with 15 min time span.

\begin{tabular}{|c|c|c|c|c|c|}
\hline & Mean & Standard Deviation & Median & Min & Max \\
\hline Traffic volume in $15 \mathrm{~min}(\mathrm{Q})$ [veh] & 633.8 & 341.2 & 583 & 216 & 1377 \\
\hline Percentage of heavy vehicles $(\mathrm{P})[\%]$ & 1.36 & 1.42 & 0.5 & 0 & 3.8 \\
\hline Total honking occurrences in $15 \mathrm{~min}(\mathrm{H})$ [counts] & 218.0 & 88.9 & 227 & 90 & 406 \\
\hline Equivalent continuous sound level $\left(L_{e q}\right)[\mathrm{dBA}]$ & 74.7 & 3.4 & 75 & 68 & 79.7 \\
\hline
\end{tabular}

\subsection{Bivariate Correlation Analysis}

A bivariate correlation analysis has been performed in $\mathrm{R}$ software framework [35]. Results are reported in Figure 3, in which traffic volume (Q), heavy vehicle percentage $(\mathrm{P})$, total honking occurrences $(\mathrm{H})$ and measured equivalent continuous sound pressure level $\left(L_{e q}\right)$ are reported with bivariate scatter plots below the diagonal, histograms on the diagonal and the Pearson correlation above the diagonal. A high correlation (0.90) is found between $L_{e q}$ and traffic volume, as expected since the main noise sources in the measurement sites are the vehicles. A significant (0.65) correlation is found between $L_{e q}$ and $\mathrm{P}$, as well as between $L_{e q}$ and $\mathrm{H}$. 

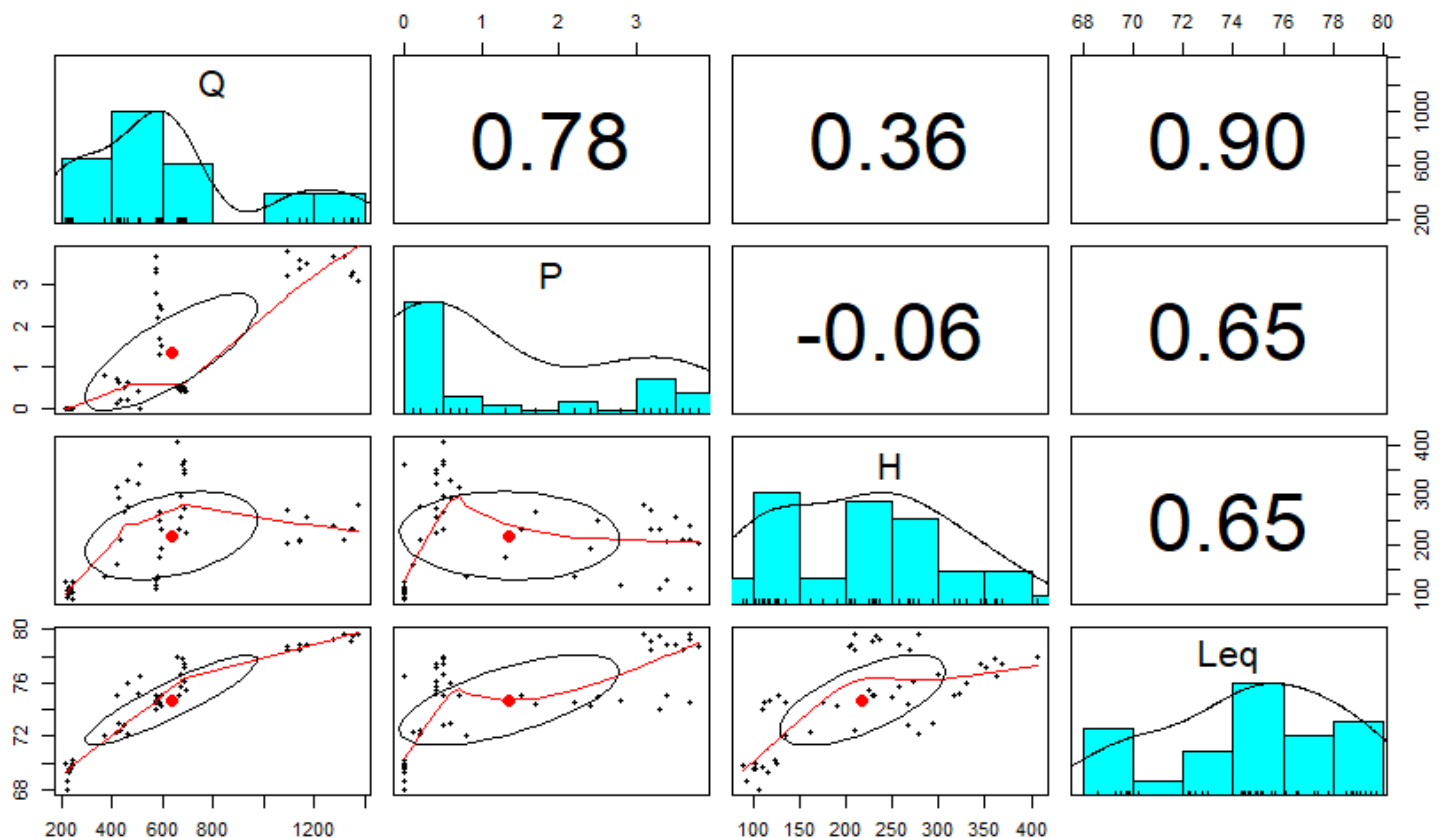

Figure 3. Scatter plot of traffic volume $(\mathrm{Q})$, heavy vehicles percentage $(\mathrm{P})$, honking occurrences $(\mathrm{H})$ and measured continuous equivalent levels $\left(L_{e q}\right)$, with bivariate scatter plots below the diagonal, histograms on the diagonal and the Pearson correlation above the diagonal.

It is interesting to notice that the heavy vehicle percentage, that is usually implemented in the most common road traffic noise models, being recognized as an important parameter of the phenomenon, correlates with the noise levels similarly to the total honking occurrences, that is practically always neglected. In the authors' opinions, this means that, at least in the five test sites and in all the sites with similar features, the honking events cannot be ignored when designing and calibrating an effective traffic noise model.

\subsection{Machine Learning Methodologies}

The traffic noise prediction models were developed using four machine learning methods in R software [35], namely decision trees (DT), random forests (RF) [36], generalized linear models (GLM) and artificial neural networks (ANN) [24,25]. These methods have been implemented in the 'Rattle' (R) software [37] which is open source and has a GNU (general public license).

The different machine learning methodologies used in the present work are briefly described below:

(i). Decision Trees (DT) [18]: These methodologies are employed in machine learning applications where an analysis of the data is required. They use a structure which resembles a flow chart as they are based on deterministic data structures and used in classification problems. At the top of the tree, there is a root node and the branches represent the tests that are done and the leaves denote the results of the tests. The rpart( ) function builds a decision tree model. A decision tree works by splitting nodes into sub-nodes. The parameter MinSplit describes the minimum number of members that a node should have before the split is attempted. MaxDepth indicates the maximum depth or length of the tree, starting from the root node up to the leaf node. MinBucket parameter specifies the minimum number of entities that a leaf node can have. The default value is generally one-thirds of the MinSplit value.

(ii). Random Forests (RF) [36]: In this approach, groups of decision trees are created. This is an ensemble method, which can be used for regression, classification and other tasks. They avoid over-fitting, which can be a drawback in the decision tree method, by making random decision forests. The observations are used as input for each tree and the most common outcome is used as the final output. As the errors are cancelled 
out, a more accurate prediction is obtained using this method. The randomForest( ) function is used for the implementation of the random forests. Breiman (2001) [36] introduced the idea of random sampling of variables at each node as the tree is being built. He also introduced the bagging concept for the sampling [38] in which random samples are chosen for the training dataset for each tree. It helps in making the model robust to noise and outliers. The parameter ntree specifies the number of trees built in the Random Forests model.

(iii). Linear Models: Generalized linear models (GLM) make use of and combine different types of regression, e.g., linear and logarithmic [39]. They take care of different types of distribution like the log-linear and log-odds, as the response is not always linear and might not follow a normal distribution.

(iv). Neural Networks [40]: Artificial neural networks (ANN) are similar in working to the human brain which uses neurons (connections of nodes) for the learning tasks. The process involves the assignment of weights to the inputs and activation functions for getting the desired outputs. There are different layers in a neural network like an input layer, a hidden layer (which performs non-linear transformations of the inputs) and an output layer of neurons. The function neuralnet( ) is used to build a neural network model in R software [35]. The parameter hlayers is used to specify the number of hidden layer nodes or neurons in the NN architecture. MaxNWts sets the maximum limit of the number of weights that can be used in the model. The maxit parameter defines the maximum number of iterations to be done during the training.

The values of the training hyperparameters for the different methods have been taken based on experience and literature survey and are briefly given below.

For the decision trees, the value of MinSplit used is 20, MaxDepth 30 and MinBucket 7. The type of random forest used in RF is regression. The number of trees is 500 and the number of variables tried at each split is 1 . The sampling type is bagging. In the neural networks, the number of hidden layer nodes or neurons is 10 with one hidden layer, epochs 150 and the batch size is 8. The activation function used is Sigmoid, dropout rate is 0.2 , number of units is 30 and the learning rate is 0.01 . The optimizer used is Grid Search. Some of the values, along with names of modules, are given in Table 2.

Table 2. Machine Learning Methods Used [41].

\begin{tabular}{cccc}
\hline Model & Method & Name of Module & Input Parameters and Values \\
\hline Decision Trees & rpart & Rpart & MinSplit $=20$, MaxDepth $=30$, MinBucket $=7$ \\
\hline Random Forests & rf & randomForest & ntree $=500$, sampling $=$ bagging \\
\hline Linear Models & $\mathrm{lm}$ & glm & None \\
\hline Neural Networks & neuralnet & Neuralnet & hlayers $=10$, MaxNWts $=10,000$, maxit $=100$ \\
\hline
\end{tabular}

\subsection{Perfomance Metrics}

The results obtained by using the methods described above were compared on the basis of the criteria of correlation coefficient $(r)$, coefficient of determination $\left(R^{2}\right)$, mean square error (MSE) and accuracy, briefly resumed in this subsection.

\subsubsection{Correlation Coefficient ( $\mathrm{r}$ )}

The correlation coefficient $(r)$ is a measure of a linear correlation between two sets of data. In particular, it measures the closeness of the points in a scatter plot to the linear regression obtained on the basis of the input data. This parameter can be evaluated as follows [42]:

$$
\mathrm{r}=\frac{\operatorname{Cov}(X, Y)}{\sqrt{s_{x}^{2} s_{y}^{2}}}
$$


where $\operatorname{Cov}(X, Y)$ is the covariance and $s_{x}^{2}$ and $s_{y}^{2}$ are the sample variance for $X$ and $Y$. Obviously, a coefficient of correlation close to 1 indicates a strong linear correlation while a coefficient $r$ close to 0 suggests a little correlation between the investigated parameters.

\subsubsection{Coefficient of Determination $\left(\mathrm{R}^{2}\right)$}

The coefficient of determination $R^{2}$ provides the percentage variation in $Y$ explained by $X$-variable. It is the square of the coefficient of correlation (r) therefore it is a measurement used to explain how much variability of one factor can be caused by its relationship to another related factor. When the coefficient of determination is equal to 1 , the regression line fits all the sample data [42].

\subsubsection{Mean Squared Error (MSE)}

MSE is a measure of the difference between the measured and the predicted values. It is a sample standard deviation of the differences between the observed values and those predicted by the model. These are called residuals when the differences are calculated for the sample (called in-sample) points, that were used to make the model and prediction errors when the calculations are done for out-of-sample data points. It is calculated as [42]:

$$
\text { MSE }=\frac{\sum_{i=1}^{n}\left(b_{i}-a_{i}\right)^{2}}{n}
$$

where, $a$ is the observed value, $b$ is the predicted value and $n$ is the number of sample data points.

\subsubsection{Accuracy}

The accuracy is defined in percentage as the mean of the number of the differences between the predicted and the observed values of the dependent variable, that fall within a given range $e$ (i.e., within an acceptable error) [28,41]. It can be calculated as follows:

$$
\begin{gathered}
\text { Acc }=\frac{100}{n} \sum_{i=1}^{n} c_{i} \\
c_{i}=\left\{\begin{array}{l}
1, \text { if } \operatorname{abs}\left(b_{i}-a_{i}\right) \leq e \\
0, \text { otherwise }
\end{array}\right.
\end{gathered}
$$

where, $b$ is the predicted value of dependent variable, $a$ is the observed value of dependent variable, $e$ is the acceptable value of error and $n$ is the total number of samples.

The results obtained are presented in the subsequent section.

\section{Results and Model Comparison}

The results obtained by using the four machine learning models are compared on the basis of $r, R^{2}$, MSE and accuracy. The above relation has been used for an accuracy of $\pm 1 \mathrm{dBA}$. The values of the different criteria for the four models are shown in Table 3.

Table 3. Comparison of results for the prediction models in the training phase.

\begin{tabular}{ccccc}
\hline Machine Learning Method & $\mathbf{r}$ & $\mathbf{R}^{\mathbf{2}}$ & $\begin{array}{c}\text { MSE } \\
{[\mathbf{d B A}]}\end{array}$ & $\begin{array}{c}\text { Accuracy }( \pm \mathbf{1} \mathbf{d B A}) \\
{[\%]}\end{array}$ \\
\hline $\begin{array}{c}\text { Decision Trees } \\
\text { (DT) }\end{array}$ & 0.935 & 0.876 & 0.884 & 68 \\
$\begin{array}{c}\text { Random Forests } \\
\text { (RF) }\end{array}$ & 0.987 & 0.975 & 0.413 & 94 \\
$\begin{array}{c}\text { Generalized Linear Model } \\
\text { (GLM) }\end{array}$ & 0.974 & 0.949 & 0.616 & 82 \\
$\begin{array}{c}\text { Neural Networks } \\
\text { (ANN) }\end{array}$ & 0.974 & 0.949 & 0.616 & 82 \\
\hline
\end{tabular}


It is seen that random forests performs better than other models in the training phase, in the criteria of $r, R^{2}$, MSE and accuracy. The value of MSE is 0.413 for $r f$ which is the lowest and the value of accuracy is $94 \%$ (for $\pm 1 \mathrm{dBA}$ ) which is the highest among all other models.

However, for a proper comparison, a testing dataset check was performed, in order to avoid overfitting.

In order to meet this objective, the dataset was split into $70 / 30$ as training and testing data, respectively. Following the training, using the $70 \%$ data, the models were tested on the testing dataset (30\%). This was done 10 times (ten-fold cross validation) for the best performing model in order to check the stability and robustness of the model. The results obtained from the testing dataset show that the generalized linear model (GLM) performs better on the considered criteria, as seen in the Table 4 .

Table 4. Comparison of results for the prediction models (testing dataset).

\begin{tabular}{ccccc}
\hline Machine Learning Method & $\mathbf{r}$ & $\mathbf{R}^{\mathbf{2}}$ & $\begin{array}{c}\text { MSE } \\
{[\mathbf{d B A}]}\end{array}$ & $\begin{array}{c}\text { Accuracy }( \pm \mathbf{1 . 0} \mathbf{d B A}) \\
{[\%]}\end{array}$ \\
\hline $\begin{array}{c}\text { Decision Trees } \\
\text { (DT) }\end{array}$ & 0.797 & 0.636 & 1.780 & 40.0 \\
$\begin{array}{c}\text { Random Forests } \\
\text { (RF) }\end{array}$ & 0.955 & 0.913 & 0.797 & 60.0 \\
$\begin{array}{c}\text { Generalized Linear Model } \\
\text { (GLM) }\end{array}$ & 0.965 & 0.933 & 0.666 & 80.0 \\
$\quad \begin{array}{c}\text { Neural Networks } \\
\text { (ANN) }\end{array}$ & 0.959 & 0.921 & 0.717 & 73.3 \\
\hline
\end{tabular}

As seen in Table 4, the value of mean square error is the lowest (0.666) for the generalized linear model (GLM) and the accuracy is highest (80.0\%). The values of MSE and accuracy obtained with neural networks are 0.717 and $73.3 \%$ respectively. Random forests and neural networks might give better results for bigger datasets but for the present case, GLM has outperformed the other models.

Results of the models' predictions plotted versus measured equivalent levels in the validation and training datasets are shown in Figure 4. It is easy to see that apart from decision trees (DT) that in 4 points is very far from the measured $L_{e q}$, all the models results are gathered almost close to the bisector, meaning a general effectiveness of the proposed models. When the measured $L_{e q}$ are around $70 \mathrm{dBA}$ (site 2), the models have the best performances. This site is characterized by absence of heavy vehicles and honking frequencies lower than in the other sites. Data above $78 \mathrm{dBA}$ are related to site 4 , in which the traffic flows are higher than in the other sites.

A scatter plot between the measured and predicted values of $L_{e q}$ for the four methods is shown in Figure 5.

A ten-fold cross validation was also performed for the best performing model, GLM and the results are shown in Figure 6. A general stability of the results is observed, confirming the goodness of the model and the suitability to be used in such applications, on noise data that includes a relevant contribution from honking. 


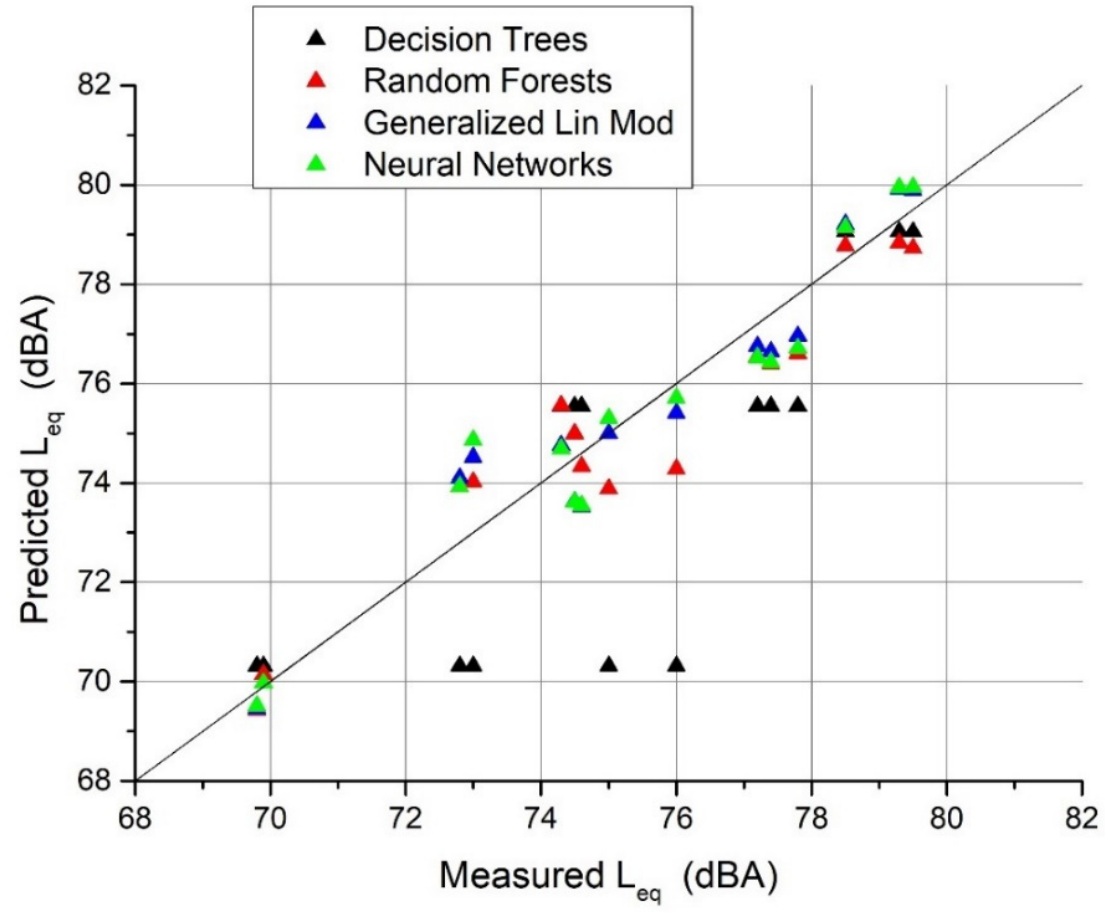

Figure 4. Scatter plot of the models' predictions versus measured equivalent levels in the training dataset. The black solid line is the bisector and is used as a guide for the eye, to easily identify overestimation and underestimation of the models.
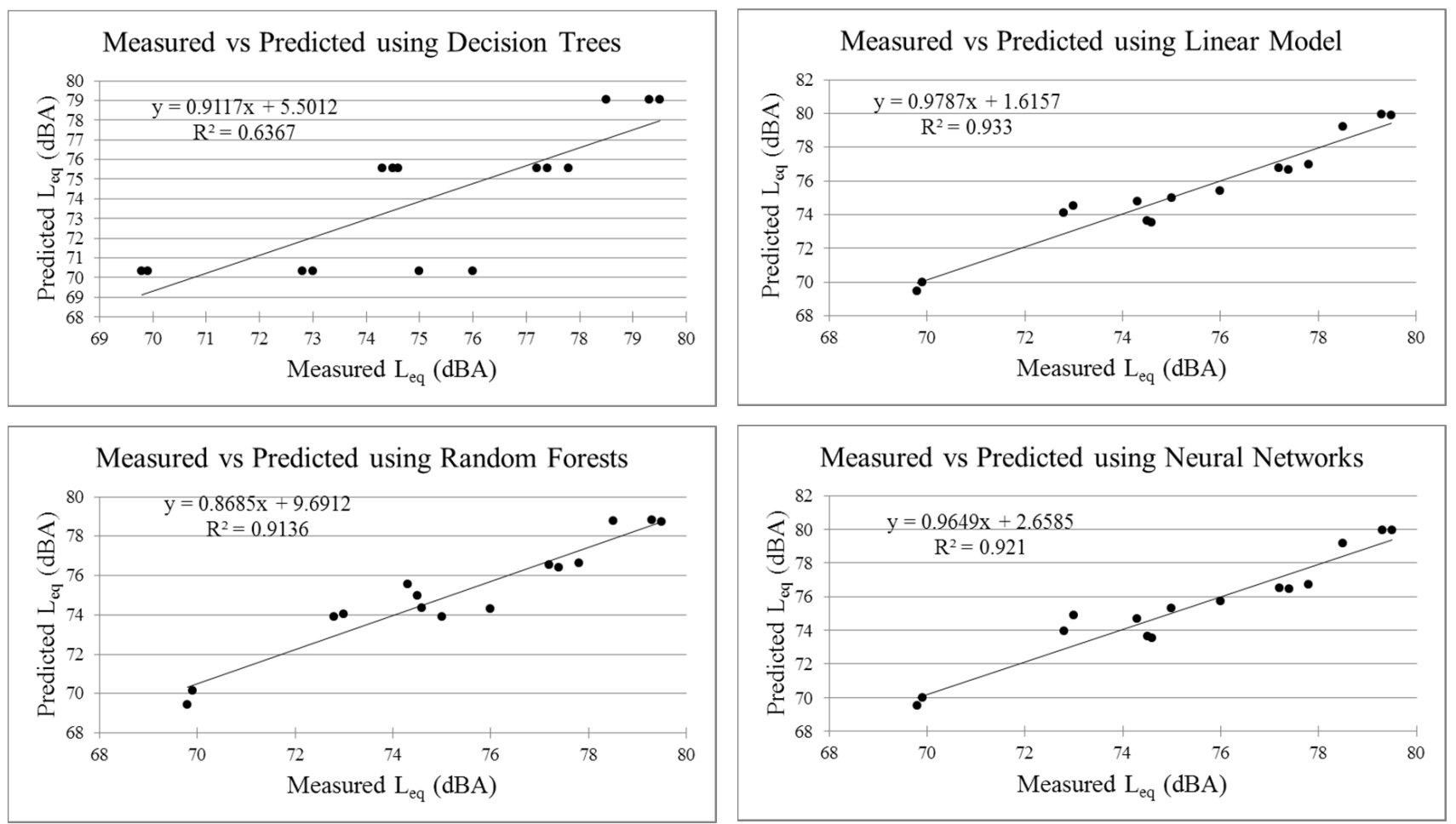

Figure 5. Scatter plots between measured and predicted values of $L_{e q}$. 


\section{Cross Validation of Correlation}

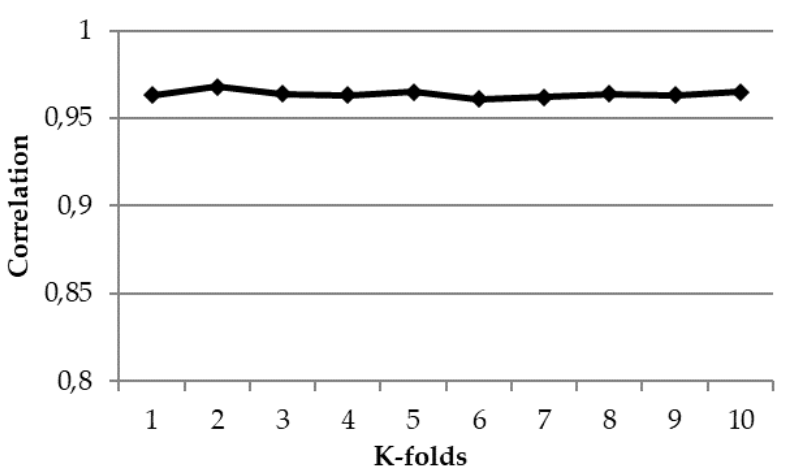

Cross Validation of $\mathbf{R}^{2}$

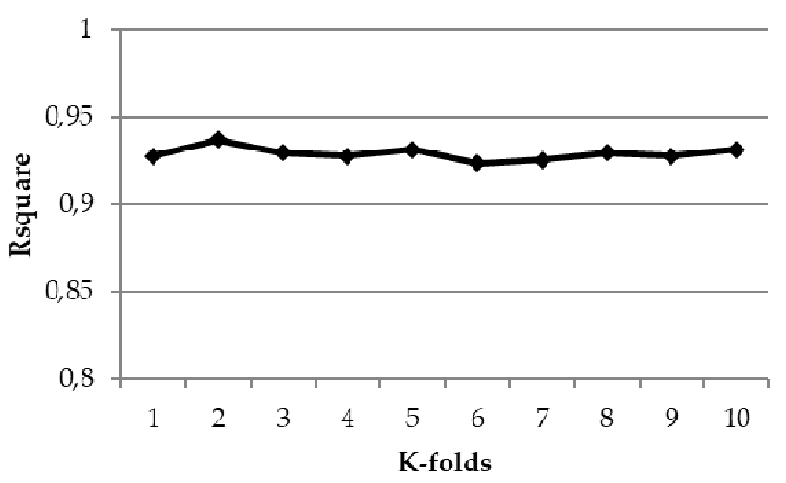

Cross Validation of MSE

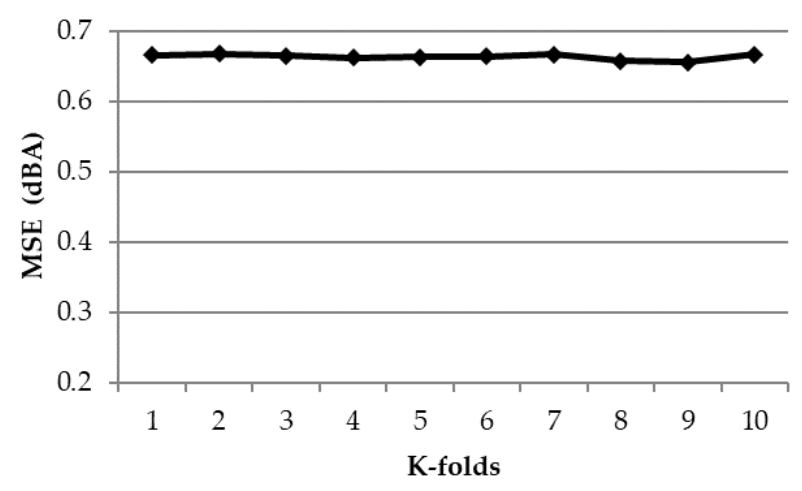

Cross Validation of Accuracy

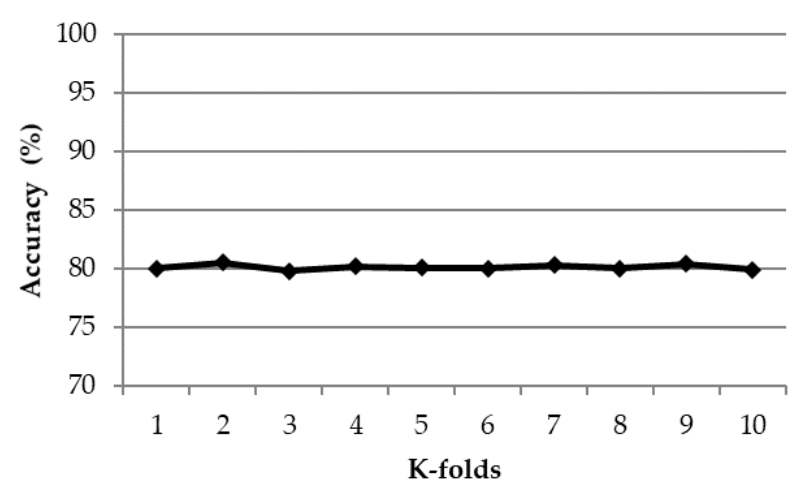

Figure 6. A ten-fold cross validation for $r, R^{2}$, MSE and accuracy for the generalized linear model (GLM).

\section{Discussion}

The results reported in Section 3 inspire interesting discussions and allow to draw some preliminary conclusions.

Looking at the scatter plot reported in Figure 4, it is easy to see that, apart from decision trees (DT), some points underestimate the measured $L_{e q}$ and all the models' results are gathered almost close to the bisector, meaning a general effectiveness of the proposed models. When the measured values of $L_{e q}$ are around $70 \mathrm{dBA}$ (site 2), the models have the best performance. This site is characterized by the absence of heavy vehicles and honking occurrences lower than in the other sites.

Data above $78 \mathrm{dBA}$ are also associated with good performances of the models. These points are related to site 4 , in which the traffic volumes are higher than in the other sites.

Finally, the larger dispersion is observed in the middle range of noise levels. In this range basically all the models produce results that are different with respect to the observed noise levels. There is not a clear pattern of overestimation or underestimation, meaning that these errors are basically random for all the models. Only the data comprised in the range 77-78 dBA seems to show a general underestimation of the models. These points belong to site 5 , in which the highest mean honking occurrences has been observed.

In order to highlight the importance of the honking inclusion in the models, a simulation without the honking parameter has been performed on the same dataset, both in training and testing phases. Results of the performance metrics without honking are reported in Tables 5 and 6 . 
Table 5. Comparison of results for the prediction models in the training phase (without considering honking).

\begin{tabular}{ccccc}
\hline Machine Learning Method & $\mathbf{r}$ & $\mathbf{R}^{2}$ & $\begin{array}{c}\text { MSE } \\
{[\mathbf{d B A}]}\end{array}$ & $\begin{array}{c}\text { Accuracy ( } \pm \mathbf{1} \text { dBA) } \\
{[\%]}\end{array}$ \\
\hline $\begin{array}{c}\text { Decision Trees } \\
\text { (DT) }\end{array}$ & 0.933 & 0.871 & 0.902 & 64 \\
$\quad \begin{array}{c}\text { Random Forests } \\
\text { (RF) }\end{array}$ & 0.978 & 0.957 & 0.526 & 82 \\
$\begin{array}{c}\text { Generalized Linear Model } \\
\quad(\mathrm{GLM})\end{array}$ & 0.904 & 0.818 & 1.182 & 40 \\
$\quad \begin{array}{c}\text { Neural Networks } \\
(\text { (ANN) }\end{array}$ & 0.904 & 0.818 & 1.182 & 40 \\
\hline
\end{tabular}

Table 6. Comparison of results for the prediction models (testing dataset) without considering honking.

\begin{tabular}{ccccc}
\hline Machine Learning method & $\mathbf{r}$ & $\mathbf{R}^{\mathbf{2}}$ & $\begin{array}{c}\text { MSE } \\
{[\mathbf{d B A}]}\end{array}$ & $\begin{array}{c}\text { Accuracy }( \pm \mathbf{1 . 0} \mathbf{d B A}) \\
{[\%]}\end{array}$ \\
\hline $\begin{array}{c}\text { Decision Trees } \\
\text { (DT) }\end{array}$ & 0.798 & 0.637 & 1.781 & 40.0 \\
$\quad \begin{array}{c}\text { Random Forests } \\
\quad(\mathrm{RF})\end{array}$ & 0.955 & 0.913 & 0.809 & 66.7 \\
$\begin{array}{c}\text { Generalized Linear Model } \\
\quad(\mathrm{GLM})\end{array}$ & 0.880 & 0.774 & 1.291 & 46.7 \\
$\quad \begin{array}{c}\text { Neural Networks } \\
(\text { (ANN) }\end{array}$ & 0.880 & 0.774 & 1.291 & 46.7 \\
\hline
\end{tabular}

Comparing with results reported in Tables 3 and 4, it can be noticed that the inclusion of honking in the modeling leads to an overall improvement of the performance metrics. The DT model seems to be not sensible to honking, since the metrics are basically constant with and without honking inclusion, both in training and testing phases. RF in testing dataset keeps $r$ and $\mathrm{R}^{2}$ basically constant, the accuracy has a little increase from $60.0 \%$ to $66.7 \%$, but MSE increases from $0.797 \mathrm{dBA}$ to $0.809 \mathrm{dBA}$. The other two models, namely GLM and ANN, converge to similar predictions and, consequently, to equal performance metrics. They exhibit a worsening of all the selected metrics when honking is not considered. Since GLM was the best performing model in the training dataset with honking, it is evident that the inclusion of this parameter leads to a better prediction of noise levels in the presented application. When honking is not included, the MSE of GLM increases from $0.666 \mathrm{dBA}$ to $1.291 \mathrm{dBA}$ and the GLM accuracy gets worse, lowering from $80 \%$ to $46.7 \%$.

Regarding the cross validation of GLM, the ten-fold cross validation results reported in Figure 6 shows a general stability. This confirms the goodness of the model and the suitability to be used in such applications, on noise data that includes a relevant contribution from honking.

Although the dataset is sufficient for the present study, a bigger dataset with a greater spread across different times of the year and more sites can be prepared and utilized in a future study. A limitation of the present study, in fact, is that the models are region-specific, since they are based on the data collected at the specific sites identified for the assessment.

The number of input parameters is limited to three in the present work (i.e., traffic volume $Q$, percentage of heavy vehicles $P$ and total honking occurrences $H$ ). In a future work, this number can be expanded including more parameters like speed of vehicles, different types of vehicles (e.g., two-wheelers, three-wheelers etc.) and acceleration-deceleration of vehicles, etc. Furthermore, an assessment of the actual increase in the noise level (in dBA) due to honking can be made and the effect of the duration of the different types of horns used on different vehicles needs to be studied. 


\section{Conclusions}

A traffic noise prediction approach using machine learning methods has been presented, which considers the parameter of honking noise. Horn noise contributes significantly to the overall road traffic noise in Indian road traffic conditions as well as other regions in the Indian sub-continent. Therefore, there is a need to pay attention to this important parameter while developing traffic noise models. An approach to include the effect of honking noise by considering the honking occurrences as a parameter has been illustrated with the help of a case study of the Patiala city in India. A preliminary multivariate analysis of the dataset showed that the presence of honking cannot be neglected in the cases under study. A relevant correlation with the continuous equivalent level was found. This correlation was equal to the one found between noise levels and percentage of heavy vehicles, that is a parameter commonly implemented in standard road traffic noise models.

The models developed were compared using the criteria of $r, R^{2}$, mean square error and accuracy. It is seen that the generalized linear model (GLM) and artificial neural networks (ANN) are the best performing models, with GLM doing slightly better than ANN on the considered criteria.

A simulation without honking parameter inclusion has been performed, to assess its contribution on the models' performances. Results showed that including honking leads to an improvement of the prediction, in particular for GLM, i.e., the model that best performed in the testing phase.

Also, a ten-fold cross validation has been done for the best performing model (GLM) to check the robustness of the developed model, showing an excellent stability of the technique.

It can be concluded that the machine learning approach can be used to develop traffic noise prediction models, including honking as a parameter, with considerable accuracy. The effect of changing the traffic parameters on the overall traffic noise can be assessed with the help of these models, without the actual need of experiments using the sound level meter or other equipment. Thus, the policy makers and administration can take suitable steps for noise abatement, which would be beneficial for the health and well-being of all the involved stakeholders.

Future developments of this research will be aimed at the calibration and testing of the presented models on more data, coming from different sites and with different traffic conditions, in order to enlarge the possible applications to other scenarios. Furthermore, the inclusion of further parameters, such as speed of vehicles, different types of vehicles (e.g., two-wheelers, three-wheelers etc.) and acceleration-deceleration regimes, will be a possible development of the methodology presented.

Author Contributions: Conceptualization, D.S.; methodology, D.S. and C.G.; software, D.S.; validation, D.S., A.B.F., S.M. and C.G.; formal analysis, D.S., A.B.F., S.M. and C.G.; investigation, D.S., A.B.F., S.M. and C.G.; resources, D.S., A.B.F., S.M. and C.G.; data curation, D.S., A.B.F., S.M. and C.G.; writing-original draft preparation, D.S.; writing—review and editing, D.S., A.B.F., S.M. and C.G.; visualization, A.B.F. and S.M.; supervision, D.S. and C.G. All authors have read and agreed to the published version of the manuscript.

Funding: This research received no external funding.

Data Availability Statement: The data presented in this study are available in Appendix A.

Acknowledgments: The authors are thankful to the Noise and Vibration laboratory, Mechanical Engineering Department, Thapar Institute of Engineering and Technology, Patiala, for the equipment and other support during the execution of this work. Also, the authors are thankful to Civil Engineering Department, University of Salerno for providing infrastructure and computational facilities.

Conflicts of Interest: The authors declare no conflict of interest. 


\section{Appendix A}

The dataset obtained in the measurement sites described in the paper and adopted in this study is reported in the table below. It can be used for scientific purposes, citing the source of the data and referring to this paper.

Table A1. Full dataset containing traffic volumes $(\mathrm{Q})$, percentage of heavy vehicles $(\mathrm{P})$, total honking occurrences in $15 \mathrm{~min}(\mathrm{H})$ and continuous equivalent sound level $\left(L_{e q}\right)$ for all the measurements, in all the sites.

\begin{tabular}{|c|c|c|c|c|c|}
\hline & $\begin{array}{c}\text { Progressive } \\
\text { Number }\end{array}$ & $\begin{array}{c}\text { Traffic } \\
\text { Volume }(Q) \\
\text { [veh] }\end{array}$ & $\begin{array}{l}\text { Percentage of } \\
\text { Heavy Vehicles } \\
\text { (P) }[\%]\end{array}$ & $\begin{array}{l}\text { Total Honking } \\
\text { Occurrences } \\
\text { (H) [Counts] }\end{array}$ & $\begin{array}{c}\text { Continuous } \\
\text { Equivalent } \\
\text { Sound Level } \\
\left(L_{e q}\right) \text { [dBA] }\end{array}$ \\
\hline \multirow[t]{10}{*}{ Site 1} & 1 & 570 & 3.3 & 110 & 74.0 \\
\hline & 2 & 582 & 2.2 & 135 & 74.6 \\
\hline & 3 & 574 & 3.7 & 112 & 74.5 \\
\hline & 4 & 576 & 2.8 & 118 & 74.7 \\
\hline & 5 & 585 & 1.7 & 267 & 74.4 \\
\hline & 6 & 589 & 2.5 & 249 & 74.9 \\
\hline & 7 & 572 & 3.4 & 128 & 75.1 \\
\hline & 8 & 584 & 1.3 & 175 & 74.5 \\
\hline & 9 & 593 & 2.4 & 191 & 74.3 \\
\hline & 10 & 597 & 1.5 & 231 & 75.0 \\
\hline \multirow[t]{10}{*}{ Site 2} & 11 & 216 & 0.0 & 126 & 69.9 \\
\hline & 12 & 241 & 0.0 & 102 & 70.0 \\
\hline & 13 & 238 & 0.0 & 110 & 69.7 \\
\hline & 14 & 239 & 0.0 & 102 & 69.5 \\
\hline & 15 & 220 & 0.0 & 106 & 68.0 \\
\hline & 16 & 230 & 0.0 & 115 & 69.3 \\
\hline & 17 & 226 & 0.0 & 100 & 69.5 \\
\hline & 18 & 244 & 0.0 & 123 & 70.2 \\
\hline & 19 & 219 & 0.0 & 93 & 68.6 \\
\hline & 20 & 246 & 0.0 & 90 & 69.8 \\
\hline \multirow[t]{10}{*}{ Site 3} & 21 & 513 & 0.0 & 363 & 76.5 \\
\hline & 22 & 423 & 0.6 & 293 & 73.0 \\
\hline & 23 & 419 & 0.7 & 316 & 75.0 \\
\hline & 24 & 505 & 0.4 & 322 & 75.2 \\
\hline & 25 & 464 & 0.6 & 330 & 76.0 \\
\hline & 26 & 463 & 0.2 & 278 & 72.2 \\
\hline & 27 & 450 & 0.5 & 267 & 72.8 \\
\hline & 28 & 422 & 0.1 & 161 & 72.3 \\
\hline & 29 & 433 & 0.2 & 210 & 72.5 \\
\hline & 30 & 369 & 0.8 & 135 & 72.0 \\
\hline \multirow[t]{10}{*}{ Site 4} & 31 & 1092 & 3.8 & 204 & 78.7 \\
\hline & 32 & 1315 & 3.7 & 209 & 79.7 \\
\hline & 33 & 1143 & 3.4 & 205 & 78.9 \\
\hline & 34 & 1141 & 3.6 & 210 & 78.5 \\
\hline & 35 & 1350 & 3.3 & 232 & 79.5 \\
\hline & 36 & 1169 & 3.5 & 257 & 78.8 \\
\hline & 37 & 1344 & 3.2 & 229 & 79.1 \\
\hline & 38 & 1090 & 3.2 & 268 & 78.5 \\
\hline & 39 & 1279 & 3.7 & 237 & 79.3 \\
\hline & 40 & 1377 & 3.1 & 279 & 79.7 \\
\hline
\end{tabular}


Table A1. Cont.

\begin{tabular}{cccccc}
\hline & $\begin{array}{c}\text { Progressive } \\
\text { Number }\end{array}$ & $\begin{array}{c}\text { Traffic } \\
\text { Volume (Q) } \\
\text { [veh] }\end{array}$ & $\begin{array}{c}\text { Percentage of } \\
\text { Heavy Vehicles } \\
\text { (P) [\%] }\end{array}$ & $\begin{array}{c}\text { Total Honking } \\
\text { Occurrences } \\
\text { (H) [Counts] }\end{array}$ & $\begin{array}{c}\text { Continuous } \\
\text { Equivalent } \\
\text { Sound Level } \\
\left(L_{\text {eq }}\right) \text { [dBA] }\end{array}$ \\
\hline Site 5 & 41 & 657 & 0.5 & 406 & 78.0 \\
& 42 & 663 & 0.5 & 229 & 75.1 \\
43 & 687 & 0.4 & 351 & 77.2 \\
44 & 686 & 0.5 & 368 & 77.4 \\
45 & 671 & 0.4 & 257 & 75.7 \\
46 & 689 & 0.4 & 273 & 76.1 \\
47 & 688 & 0.4 & 345 & 77.4 \\
48 & 680 & 0.5 & 360 & 77.8 \\
49 & 675 & 0.5 & 299 & 75.5 \\
\hline 50 & 690 & 0.4 & 225 & \\
\hline
\end{tabular}

\section{References}

1. Moshammer, H.; Panholzer, J.; Ulbing, L.; Udvarhelyi, E.; Ebenbauer, B.; Peter, S. Acute Effects of Air Pollution and Noise from Road Traffic in a Panel of Young Healthy Adults. Int. J. Environ. Res. Public Health 2019, 16, 788. [CrossRef]

2. Gieseke, J.; Gerbrandy, G.J. Report on the Inquiry into Emission Measurements in the Automotive Sector; Committee of Inquiry into Emission Measurements in the Automotive Sector, European Parliament: Brussel, Belgium, 2017.

3. Pascale, A.; Fernandes, P.; Guarnaccia, C.; Coelho, M.C. A study on vehicle Noise Emission Modelling: Correlation with air pollutant emissions, impact of kinematic variables and critical hotspots. Sci. Total Environ. 2021, 787, 147647. [CrossRef]

4. Zambrano-Martinez, J.L.; Calafate, C.T.; Soler, D.; Lemus-Zúñiga, L.G.; Cano, J.C.; Manzoni, P.; Gayraud, T. A centralized route-management solution for autonomous vehicles in urban areas. Electronics 2019, 8, 722. [CrossRef]

5. Babisch, W. Stress hormones in the research on cardiovascular effects of noise. Noise Health 2003, 5, 1. [PubMed]

6. World Health Organization. Environmental Noise Guidelines for the European Region; World Health Organization Regional Office for Europe UN City: Copenhagen Ø, Denmark, 2018.

7. Banerjee, D. Research on road traffic noise and human health in India: Review of literature from 1991 to current. Noise Health 2012, 14, 113.

8. Silva, L.T.; Oliveira, I.S.; Silva, J.F. The impact of urban noise on primary schools. Perceptive evaluation and objective assessment. Appl. Acoust. 2016, 106, 2-9. [CrossRef]

9. Win, K.N.; Balalla, N.B.P.; Lwin, M.Z.; Lai, A. Noise-Induced Hearing Loss in the Police Force. Saf. Health Work 2015, 6, 134-138. [CrossRef] [PubMed]

10. Rice, C. CEC joint research on annoyance due to impulse noise: Laboratory studies. In Proceedings of the Fourth International Congress on Noise as A Public Health Problem, Turin, Italy, 21-25 June 1983; Volume 2, pp. 1073-1084.

11. Frei, P.; Mohler, E.; Röösli, M. Effect of nocturnal road traffic noise exposure and annoyance on objective and subjective sleep quality. Int. J. Hyg. Environ. Health 2014, 217, 188-195. [CrossRef]

12. Singh, D.; Nigam, S.P.; Agrawal, V.P.; Kumar, M. Modelling and Analysis of Urban Traffic Noise System Using Algebraic Graph Theoretic Approach. Acoust. Aust. 2016, 44, 249-261. [CrossRef]

13. Steele, C. A critical review of some traffic noise prediction models. Appl. Acoust. 2001, 62, 271-287. [CrossRef]

14. Garg, N.; Maji, S. A critical review of principal traffic noise models: Strategies and implications. Environ. Impact Assess. Rev. 2014, 46, 68-81. [CrossRef]

15. Quartieri, J.; Mastorakis, N.E.; Iannone, G.; Guarnaccia, C.; D'Ambrosio, S.; Troisi, A.; Lenza, T.L. A Review of Traffic Noise Predictive Models. In Recent Advances in Applied and Theoretical Mechanics, Proccedings of the Conference Applied and Theoretical Mechanics, Puerto de la Cruz, Tenerife, Spain, 14-16 December 2009; WSEAS Press: Athens, Greece, 2009; pp. 72-80.

16. Guarnaccia, C. Advanced Tools for Traffic Noise Modelling and Prediction. WSEAS Trans. Syst. 2013, 12, 121-130.

17. Kumar, K.; Parida, M.; Katiyar, V.K. Road traffic noise prediction with neural networks-A review. Int. J. Optim. Control 2012, 2, 29-37. [CrossRef]

18. Quinlan, J.R. Induction of decision trees. Mach. Learn. 1986, 1, 81-106. [CrossRef]

19. Eliseeva, E.; Hubbard, A.E.; Tager, I.B. An application of machine learning methods to the derivation of exposure-response curves for respiratory outcomes. In U.C. Berkeley Division of Biostatistics Working Paper Series; University of California: Berkeley, CA, USA, 2013; p. 309. Available online: http://biostats.bepress.com/ucbbiostat/paper309 (accessed on 1 May 2013).

20. Iannone, G.; Guarnaccia, C.; Quartieri, J. Noise Fundamental Diagram deduced by traffic dynamics. In Recent Researches in Geography, Geology, Energy, Environment and Biomedicine, Proceedings of the 4th WSEAS International Conference on EMESEG'11, Corfù Island, Greece, 14 July 2011; WSEAS Press: Athens, Greece, 2011; pp. 501-507. 
21. Quartieri, J.; Mastorakis, N.E.; Iannone, G.; Guarnaccia, C. Cellular automata application to traffic noise control. In Proceedings of the 12th WSEAS International Conference on Automatic Control, Modelling and Simulation (ACMOS'10), Sicily, Italy, 29-31 May 2010; pp. 299-304.

22. Graziuso, G.; Mancini, S.; Guarnaccia, C. Comparison of single vehicle noise emission models in simulations and in a real case study by means of quantitative indicators. Int. J. Mech. 2020, 14, 198-207. [CrossRef]

23. Cammarata, G.; Cavalieri, S.; Fichera, A. A neural network architecture for noise prediction. Neural Netw. 1995, 8, 963-973. [CrossRef]

24. Kumar, P.; Nigam, S.P.; Kumar, N. Vehicular traffic noise modeling using artificial neural network approach. Transp. Res. Part C Emerg. Technol. 2014, 40, 111-122. [CrossRef]

25. Givargis, S.; Karimi, H. A basic neural traffic noise prediction model for Tehran's roads. J. Environ. Manag. 2010, 91, 2529-2534. [CrossRef]

26. Gündoğdu, Ö.; Gökdağ, M.; Yüksel, F. A traffic noise prediction method based on vehicle composition using genetic algorithms. Appl. Acoust. 2005, 66, 799-809. [CrossRef]

27. Rahmani, S.; Mousavi, S.M.; Kamali, M.J. Modeling of road-traffic noise with the use of genetic algorithm. Appl. Soft Comput. 2011, 11, 1008-1013. [CrossRef]

28. Singh, D.; Upadhyay, R.; Pannu, H.S.; Leray, D. Development of an adaptive neuro fuzzy inference system based vehicular traffic noise prediction model. J. Ambient Intell. Hum. Comput. 2021, 12, 2685-2701. [CrossRef]

29. Guarnaccia, C.; Quartieri, J.; Tepedino, C. A hybrid predictive model for acoustic noise in urban areas based on time series analysis and artificial neural network. In AIP Conference Proceedings; AIP Publishing LLC: Melville, NY, USA, 2017; Volume 1836, p. 020069.

30. Thakre, C.; Laxmi, V.; Vijay, R.; Killedar, D.J.; Kumar, R. Traffic noise prediction model of an Indian road: An increased scenario of vehicles and honking. Environ. Sci. Pollut. Res. Int. 2020, 27, 38311-38320. [CrossRef] [PubMed]

31. Kalaiselvi, R.; Ramachandraiah, A. Honking noise corrections for traffic noise prediction models in heterogeneous traffic conditions like India. Appl. Acoust. 2016, 111, 25-38. [CrossRef]

32. Sharma, A.; Bodhe, G.L.; Schimak, G. Development of a traffic noise prediction model for an urban environment. Noise Health 2014, 16, 63-67. [CrossRef]

33. IEC 61672-1: 2002. Electroacoustics—Sound level meters_Part 1: Specifications; International Electrotechnical Commission: Geneva, Switzerland, 2002.

34. ISO 362-1: 2015. Measurement of Noise Emitted by Accelerating Road Vehicles—Engineering Method—Part 1: M and N Categories; International Organization for Standardization: Geneva, Switzerland, 2015.

35. R Core Team. R: A Language and Environment for Statistical Computing; R Foundation for Statistical Computing: Vienna, Austria, 2014. Available online: http:/ / www.R-project.org/ (accessed on 3 May 2021).

36. Breiman, L. Random forests. Mach. Learn. 2001, 45, 5-32. [CrossRef]

37. Williams, G. Rattle: A Data Mining GUI for R. R J. 2009, 1, 45-55. [CrossRef]

38. Breiman, L. Bagging Predictors. Mach. Learn. 1996, 24, 123-140. [CrossRef]

39. Nelder, J.A.; Wedderburn, R.W.M. Generalized linear models. J. R. Stat. Soc. A 1972, 135, 370-384. [CrossRef]

40. Riedmiller, M.; Braun, H. A direct adaptive method for faster backpropagation learning: The RPROP algorithm. In Proceedings of the IEEE International Conference on Neural Networks, New Jersey, NJ, USA, 28 March-1 April 1993; pp. 586-591.

41. Singh, D.; Nigam, S.P.; Agrawal, V.P.; Kumar, M. Vehicular traffic noise prediction using soft computing approach. J. Environ. Manag. 2016, 183, 59-66. [CrossRef]

42. Spiegel, M.R.; Stephens, L.J. Theory and Problems of Statistics, 3rd ed.; Schaum's Outline Series; McGraw-Hill: New York, NY, USA, 1999. 